\title{
Seaport development management based on business process modeling
}

\author{
Etibar Bagirov ${ }^{1}$, Tatiana Pantina $^{2}$, and Svetlana Borodulina ${ }^{2, *}$ \\ ${ }^{1}$ Azerbaijan State Marine Academy, Zarifa Aliyeva str. 18, AZ1000, Baku, Azerbaijan \\ ${ }^{2}$ Admiral Makarov State University of Maritime and Inland Shipping, Dvinskaya str. 5/7, 198035, \\ Saint Petersburg, Russia
}

\begin{abstract}
Increasing the production capacity of ports is seen as one of the most significant goals for the development of maritime transport infrastructure, which requires the use of adequate forecasting methods. The problem of choosing methods of management in transport in conditions of instability of cargo flows, non-stationary functioning, the need for digitalization and transformation of processes and technologies is of particular importance. Taking advantage of the process approach in the management of seaport development, such as flexibility and transparency, is becoming an effective way to increase the productivity and efficiency of maritime transport in general. The paper presents the author's presentation of the peculiarities of the process management of the seaport development. The use of the concept of modularity in managing the development of a seaport through a system of business processes is proposed. A method for assessing the significance of the seaport business processes for achieving its goals from the standpoint of their further optimization is presented. The research results presented in the paper were obtained on the basis of the description and economic and mathematical modeling of the basic business processes that form the process outputs. Using the seaport of Baku as the example, predictive models of cargo flows are described.
\end{abstract}

\section{Introduction}

The modern vector based on the digitalization of the economy has a great impact on the development of enterprises. Using the latest technology and control systems is a priority in competitive markets. Seaports are complex business systems, and their digitalization requires an adequate approach that takes into account the specifics of management (primarily - flexibility) in non-stationary conditions. Methods and styles of transport management are determined by the development trends of the transport services market. In conditions of instability in the functioning of transport enterprises and transport infrastructure, the speed of response of their business systems to disturbance factors from the external and internal environment, readiness for changes in technology and internal communications, and operational efficiency are especially important. In this regard, there is a need to develop the theory of management of transport enterprises, to substantiate

\footnotetext{
* Corresponding author: piter00000@mail.ru
} 
approaches and methods that can ensure positive changes and positive dynamics of their development, ensuring an increase in the efficiency of business processes, as well as the search for rational ways to achieve economic sustainability.

\section{Methods and materials}

In theory, there are a large number of conceptual solutions in terms of enterprise management based on an adequate response to aggressive changes in conditions and parameters of the environment that constitutes the outer shell of their life, including in the field of maritime transport. In the modern world, in order to achieve transparency of functioning, flexibility, adaptability of business processes to the needs of users, it is proposed to use, in theory and in practice, a process approach in management. This approach focuses not on individual functions of the structural components of enterprises, but on work chains integrated into various structural divisions and integrated into business processes. The process approach in enterprise management also supports the cooperation of structural links aimed at achieving the desired result. In recent years, the process approach to management has been the subject of many studies, both from a general theoretical and an applied perspective (Thomas J. Goldsby, Deepak Iyengar, Shashank Rao, 2014, Brocke, J. HKVJH \& Rosemann, M., 2010, etc.). The use of process management in transport has recently been updated. This is caused by the special importance of the transport industry, which brings together producers and consumers in different parts of the world.

For example, a study (Brocke, J. HKVJH \& Rosemann, M. (2010)) provides statistical data reflecting the role of transport in developed economies. At the same time, about $63 \%$ of logistics costs are accounted for by transportation, while the share of logistics costs in GDP is $8.5 \%$ in the USA, $12 \%$ in Europe, $21 \%$ in China The influence of water transport on the development of the Russian economy through the prism of various kinds of effects was studied in detail in our study (Pantina T., Borodulina S., 2015; Borodulina S., Pantina T., 2020). Solutions in terms of optimizing business processes in transport systems based on logistics solutions are contained in the report (L. Burgess, T. Fowler, A. Minowitz, L. Neudorff (2016)).

In the study (Kuznetsov A.L., Kirichenko A.V. et al., 2018), the authors used heuristic programming technology in solving maritime logistics problems, in particular, the problem of finding the optimal round trip and cargo consolidation in the hinterland of the seaport. Complex modeling of business processes and optimization of communications for public rail and road transport are widely presented in the study (Schnieder, Lars \& Wermser, Diederich \& Barrilero, Marta (2014)). An interesting study of the impact of the Internet of things on changing business processes in ports was carried out by Ferretti, M. and Schiavone, F. (2016).

The example of the German port of Hamburg demonstrates an increase in productivity and high efficiency in optimizing business processes through the introduction of technologies based on IoT. The authors of research in the field of process management indicate that more research comes down to studying three main methods/instruments to support the development, implementation, management and analysis of operational business processes - process description (Cummins FA, 2017; Kirchmer M., 2017), their analysis and modeling, as well as reengineering.

The topic of logistics processes in seaports has been studied from different angles and with varying degrees of detail. However, in the main focus, researchers note the increased role of information technologies for optimizing logistics processes (Elbert, R., Pontow, H. and Benlian, A., 2016; Besri, Z. and Boulmakoul, A., 2017; Heilig, L. and Voß, S. 2016; Cimino, M.G., Palumbo, F., Vaglini, G., Ferro, E., Celandroni, N., LaRosa, D., 2017). It has been proven that the use of digital space and the use of information and communication 
technologies increase the efficiency and reliability of cargo transshipment in ports, increase their competitiveness and customer loyalty. The optimization of the berthing infrastructure within the framework of the port process model is described in (Zeng, Q., Feng, Y. and Chen, Z., 2017). It is proved that the method of direct transshipment of goods reduces the expenses of the terminal and carriers. Córdova, F. and Durán, C. (2014) believe that the optimization of port performance at the strategic and operational levels requires continuous assessment of competency management. The author of this paper proposes a change in the business model for managing the seaport community based on updating the mission and performance indicators, as well as assessing the socio-economic impact of the port's activities in the city where it is located. The study (Saragiotis, P., 2019) argues that the optimization of business processes in the modern literature is recognized as the main factor of efficiency from the point of view of the result (output) and does not describe these effects from the point of view of the benefits received by the seaport, shippers, carriers and others. Studies that reflect the degree of influence of optimization of business processes on the achievement of current and strategic goals of seaports are rarely presented in modern publications.

The process approach, in our opinion, due to its advantages over the functional one, is an adequate way of organizing both operational and current, as well as strategic management. It is the basis of many modern methods and instruments of strategic management based on the use of Key Performance Indicators, including the Balanced Scorecard. Strategic process-oriented management involves a gradual transition to strengthening the position of enterprises in the market, to their development, as well as to achieving the strategic goals of economic entities. Operational process management allows preventing significant deviations in the functioning of organizations from the target strategic performance parameters. The essence of the process approach is manifested in the control of the work results, first of all, and not the technologies used to achieve them. Modern management concepts describe the main goal of enterprises in the process of achieving market positions in this way: any client relies on an individual attitude towards himself, and it is necessary to interact with a group of clients in a special way, adjusting your business processes to it. For enterprises that implement a process-oriented approach in a non-stationary market, this is the main instrument for achieving stability, which is based on deep detailing of operations, works and individual processes. This approach allows one to flexibly and clearly assign responsibility and tasks to each employee of the company and their individual groups (teams). Thus, the transition to process-oriented enterprise management becomes necessary to build capacity, increase customer focus and competitiveness in the context of complex non-stationary development dynamics.

A seaport is a complex business system described by a complex business model of operation. By the business process of a seaport, we mean the whole range of operations and related work performed in the seaport according to the technology that ensures the transition of the system of input resources based on their transformations or detailing the conditions of use into the system of outputs consumed by customers. Substantiation of the relevance of the application of the process-oriented approach in seaport management is associated with the possibility of describing various schemes and sequence of performance of port and related operations. This is caused by the peculiarities of the port operation associated with large differences in the types of cargo, ships, as well as the methods of customs clearance, and other frequently repeated operations and interactions. This allows concluding that management of the development of a seaport using process-oriented management technologies can be adequate and effective. In addition, it will allow modeling and optimization of the operational business process of cargo transshipment in the port, taking into account different options for its implementation. The target characteristics of process management in seaports include increasing the transparency of management, 
standardizing business processes, reducing the degree of influence of the "human factor" on the operations of business processes, optimizing key performance indicators of processes, increasing the key factor parameters of success and customer focus of ports, improving the manageability of the port systems as a whole. The study of the process approach in transport made it possible to describe the development strategies of seaports (Table 1).

Table 1. Characteristics of the development strategies of the seaport from the standpoint of process management.

\begin{tabular}{|c|c|c|}
\hline $\begin{array}{c}\text { Strategy } \\
\text { of }\end{array}$ & Description of the strategy & $\begin{array}{c}\text { Detailed strategy from the } \\
\text { perspective of process } \\
\text { management }\end{array}$ \\
\hline & $\begin{array}{l}\text { Parallel optimization, rationalization, } \\
\text { modernization of port services; the } \\
\text { specificity of the changes is autonomy, } \\
\text { it is not related to other management } \\
\text { objects in the port; the goal is to } \\
\text { achieve particular results that allow the } \\
\text { port to develop }\end{array}$ & $\begin{array}{l}\text { Point optimization of } \\
\text { subprocesses / operations in the } \\
\text { port. Possibility of customizing } \\
\text { and correcting business processes } \\
\text { of port management and } \\
\text { development. }\end{array}$ \\
\hline $\begin{array}{l}\text { modula } \\
\text { change }\end{array}$ & $\begin{array}{l}\text { tion of complex, non- } \\
\text { ed innovations, involving } \\
\text { of the performer's actions } \\
\text { odule. }\end{array}$ & $\begin{array}{l}\text { Transformation of a number of } \\
\text { process parameters of the port, } \\
\text { including the basic and } \\
\text { supporting business processes of } \\
\text { the port. }\end{array}$ \\
\hline & $\begin{array}{l}\text { Comprehensive reorganization of } \\
\text { activities (transformation of goals, } \\
\text { objectives, content, organization, } \\
\text { technologies), structures, links, } \\
\text { connections, sections, as well as a } \\
\text { change in the overall status of the port. }\end{array}$ & $\begin{array}{l}\text { Transition to process-oriented } \\
\text { management in the seaport, } \\
\text { reengineering procedures for the } \\
\text { port's business processes that } \\
\text { affect the achievement of } \\
\text { strategic goals }\end{array}$ \\
\hline
\end{tabular}

The concept of modularity is rarely used in economics, and, first of all, it is rarely used to describe the issues of digitalization of the economy. In our opinion, the use of the concept of modularity in decisions related to the implementation of process-oriented management in the seaport will ensure transparency and clarity of decisions and actions aimed at implementing the port development strategy.

\section{Results and discussion}

Each business process has a specific purpose. The goals of business processes describe the benchmarks for the development of the lower level of the organization, the achievement of which, in combination, leads to the implementation of the goals of the upper level of port development. By managing and optimizing business processes, the management of the seaport can achieve an increase in operational efficiency associated with the indicators of strategic development. The nature of the influence of business processes on the achievement of its strategic goals by the seaport is shown in Fig. 1. 


\begin{tabular}{|l|l|}
\hline \multicolumn{2}{|c|}{ Seaport development management goals (Gi) } \\
\hline $\mathrm{G}_{1}$. Increase in the efficiency of cargo transshipment \\
$\mathrm{G}_{2}$. Increase in the efficiency of cargo handling in the seaport \\
$\mathrm{G}_{3}$. Increase in the quality of service for ships and cargo \\
$\mathrm{G}_{4}$. Increased transparency and flexibility of the seaport com- \\
munications system \\
\hline $\mathrm{G}_{5}$. Meeting the needs of cargo owners \\
\hline $\mathrm{G}_{6}$. Obtaining target profit / or its growth in the short term \\
\hline $\mathrm{G}_{7}$. Sustainable long-term profit growth \\
\hline $\mathrm{G}_{8}$. Stable long-term interaction with clients and counterparties \\
\hline $\mathrm{G}_{9}$. Growth of strategic potential (technological, resource, \\
technical, economic and others) \\
\hline $\mathrm{G}_{10}$. Meeting the needs of shipping lines \\
\hline
\end{tabular}

Fig. 1. Influence of business processes on the implementation of the goals of seaports.

As fig. 1 shows, the basic business processes are the most important in terms of achieving the development goals of seaports. The basic operational processes of the ports can be classified by categories: by the nomenclature of the cargo, by the external economic regime, by the mode of transport when importing and exporting cargo, by the place of customs clearance of the cargo and by the type of cargo flow. Detailing in the category of the nomenclature of cargo and by the type of transport for import and export of cargo is based on the statistics of the port's cargo turnover and data on the arrival of cargo at the port with the separation of land and sea transport. Detailing is also supposed to be carried out for cargo arriving at the port by different modes of transport - sea, pipeline, road, rail. Detailing in terms of the external economic regime reflects the possibility of performing a business process in transit, export, and import modes, as well as the passage of cargo inside the port territory.

Detailing by places of customs clearance of goods is associated with the peculiarity of these operations in the port, according to which the places of customs clearance of goods can be located either before arrival at the port at external terminals equipped with customs posts (road, rail delivery of goods to the port), or inside the port. Thus, three main business processes can be distinguished in a seaport: cargo admission to the port, cargo handling in the port, and cargo removal from the port. The selected processes differ in decomposed sub-processes, depending on the import and export regime, as well as depending on the nomenclature of the cargo and the method of arrival of the cargo delivered to the port. Next, the business process is decomposed depending on the conditions of its course. The use of the process description of the seaport business model will provide flexibility and transparency in the management of operations, develop exactly those areas that are either the most problematic or seem to be priorities in the development of the port.

It is advisable to describe the importance of business processes or sub-processes of the seaport for achieving its goals from the standpoint of their further optimization using the methods of economic and mathematical modeling. For example, the description of the importance of port processes in achieving development goals can be carried out using the method of hierarchy analysis (T. Saaty, 1999). The description of the criteria for achieving the goals and parameters of the development of the seaport in the form of hierarchical elements will allow highlighting the chains of importance of business processes. In this analysis, seaport cargo turnover (P) can be selected as the top-level criterion. The criteria of the first level of the hierarchy, depending on the development goals of the port, are divided into subgoals G1...G10 shown earlier in the table. Achievement of these Gi subgoals leads to an increase in the target value of cargo turnover $(\mathrm{P})$. The second-level criteria may include areas of port development, such as infrastructure (I), resources (R), position of the 
port in the external environment (E), quality of the internal system of business processes and communications (BPC). Then, as a result of modeling, an optimal chain can be obtained from the point of view of achieving the goal (growth of freight turnover P):

$$
\mathrm{BP}_{\mathrm{j}} \rightarrow\left\{\begin{array}{l}
\mathrm{I} \\
\mathrm{R} \rightarrow\left(\mathrm{G}_{1} \ldots \mathrm{G}_{10}\right) \rightarrow \mathrm{P} \\
\mathrm{E} \\
\mathrm{BPC}
\end{array}\right.
$$

Decomposition of the $\mathrm{BPj}$ business process into its main operations in order to identify the main problems and optimization opportunities will complement the method. The structure of a business process can be represented by a set of characteristics - input resources, resource-instruments and control inputs, as well as outputs, and indicators that quantitatively describe them. Therefore, it is necessary to highlight the basic indicators that have a high level of significance for monitoring the status and development of the port based on business processes (Table 2).

Table 2. Significant indicators of the boundaries of the basic business processes of the seaport.

\begin{tabular}{|c|c|c|c|c|}
\hline $\mathrm{BP}_{\mathrm{j}}$ & Process inputs & Process resources & Process control & $\begin{array}{l}\text { Process } \\
\text { outputs }\end{array}$ \\
\hline $\begin{array}{c}\qquad \mathrm{BP}_{1} \\
\text { cargo } \\
\text { admission } \\
\text { to the port }\end{array}$ & \multirow{2}{*}{$\begin{array}{l}\text { Number of ship } \\
\text { calls }(N v) \text {; number } \\
\text { of vehicles passing } \\
\text { through the port } \\
\text { gates per unit of } \\
\text { time }(T) \text {; number of } \\
\text { loaded trains }(N r w)\end{array}$} & \multirow[b]{2}{*}{$\begin{array}{c}\text { storage space } \\
\text { utilization, \% }(S L U)\end{array}$} & \multirow{2}{*}{$\begin{array}{l}\text { time of business process } \\
\text { execution in import mode } \\
\text { (Tbpli; Tbp } 3 i) \text {; in export } \\
\text { mode }(T b p l e ; T b p 3 e) ; \\
\text { number of cases of damage } \\
\text { to goods in the seaport due } \\
\text { to the fault of the personnel, } \\
\text { which led to the insured } \\
\text { event, with the fixation of } \\
\text { claims }(Q)\end{array}$} & - \\
\hline $\begin{array}{c}\mathrm{BP}_{3} \\
\text { removal } \\
\text { of cargo } \\
\text { from the } \\
\text { port }\end{array}$ & & & & $Q$ \\
\hline $\begin{array}{c}\mathrm{BP}_{2} \\
\text { handling } \\
\text { of cargo } \\
\text { in the port }\end{array}$ & - & $\begin{array}{l}\text { the degree of use of } \\
\text { the storage space for } \\
\text { the placement of } \\
\text { goods, } \%(S S U) ; \\
\text { business process } \\
\text { execution time } \\
(T b p 2) ; \\
\text { operational staff } \\
\text { productivity }(L P)\end{array}$ & $\begin{array}{l}\text { frequency of monitoring } \\
\text { work (number of control } \\
\text { points) with cargo in the } \\
\text { port per unit of time }(M)\end{array}$ & - \\
\hline
\end{tabular}

A quantitative description of business processes in the form of a system of indicators will allow for their operational control and management, as well as substantiating the most expedient ways of port development on the basis of a process business model. And the parameters presented in Table 2 can serve as elements of the process control module. The process description of the functioning will make it possible to adjust the parameters and operating conditions of the seaport processes through modular process changes. This means that by creating new conditions or adjusting the traditional schemes for the execution of operations or their sequence and content (innovations), the input and output modules of business processes will be subject to changes. It is supposed to monitor the impact of modular changes on the development of ports by analyzing transformations in the system of indicators of changes in boundaries - inputs and outputs of the basic business processes, an example of which for operational business processes is given in Table 2.

Based on the modules of the seaport business processes, it is also possible to forecast the results of its work. So, based on the systematization of the information of the sea trade 
port of Baku (Bagirov E.A., Borodulina S.A., 2017), the modeling of cargo turnover for different types of cargo in the form of import and export cargo flows for the basic business processes was carried out. Calculations of the partial correlation coefficients made it possible to assert that the change in the turnover of the port of Baku is closely dependent on the change in the selected indicators of the process boundaries. As an example of forecasting outbound and inbound cargo flows, the obtained dependencies for container cargo are presented below:

- export cargo flow $(\mathrm{Pe})$ :

$$
P e=6990.59+122.99 \cdot \mathrm{Nrw}+47.83 \cdot \mathrm{T}-961.73 \cdot \text { Tbple }-337.86 \cdot Q
$$

$\mathrm{R}^{2}=0.94 ; \mathrm{F}=39.5>\mathrm{Ft}(4 ; 10)=3.48$, strong link, equation statistically reliable.

- import cargo flow (Pi):

$$
P i=-1921.57+2364.66 \cdot N v+64.75 \cdot T b p 1 i+244150.45 \cdot S L U-255.14 * Q
$$

$\mathrm{R}^{2}=0.82 ; \mathrm{F}=11,5,5>\mathrm{Ft}$, strong link, equation statistically reliable.

The assessment of the impact of modular changes on the parameters of the seaport development can be carried out using the described correlation models for the selected target indicators of the port. When using them, it is necessary to use the most significant indicators of business processes, the values of which can be transformed under the influence of modular changes. The resulting models will make it possible to estimate changes in target indicators in the forecast as a result of the introduction of certain modular changes. At the same time, changing the input parameters during the simulation of the result will allow seeing the future performance of the port and comparing the obtained values with the target values. This, in particular, will make it possible to substantiate decisions related to investment, modernization and optimization of process parameters.

\section{Conclusions}

Justification of decisions in the field of management of a complex business model of a seaport requires the use of adequate methods and instruments that allow flexible customization and transformation of individual operations and technologies. The use of process management in substantiating the optimal areas for the development of seaports will make it possible to see the chains of interconnection of process transformations with a change in the target parameters of development. In addition, the paper substantiates that the use of process management will make it possible to predict the results of the port's functioning when implementing modular changes in its business processes. Further research can be focused on aggregating the results of forecast cargo flow data and adapting resource parameters by optimizing development areas.

\section{References}

1. T. J. Goldsby, D. Iyengar, S. Rao, Definitive Guide to Transportation: Principles, Strategies, and Decisions for the Effective Flow of Goods and Services by CSCMP (Pearson FT Press, 2014) https://www.informit.com/articles/article.aspx?p=2171313, last accessed 2021/02/23

2. J. Brocke, M. Rosemann, Handbook on Business Process Management: Strategic Alignment, Governance, People and Culture (International Handbooks on Information Systems), 1 (Springer, Berlin, 2010) 
3. T. A. Pantina, S. A. Borodulina, Review of European Studies 7(9), 83-96 (2015) DOI: 10.5539 / res.v7n9p83

4. S. Borodulina, T. Pantina, Model of sustainable economic development in the context of inland water transport management, 806-819 (Springer, Cham, 2020) DOI: https://doi.org/10.1007/978-3-030-57450-5_68

5. L. Burgess, T. Fowler, A. Minowitz, L. Neudorff, Improving Business Processes for More Effective Transportation Systems Management and Operations. Federal Highway Administration

https://ops.fhwa.dot.gov/publications/fhwahop16018/fhwahop16018.pdf, last accessed 2021/02/21

6. A. L. Kuznetsov, A. V. Kirichenko, A. E. Sazonov, G. B. Popov, Marine Intelligent Technologies 4-4(42), 224-228 (2018) https://www.elibrary.ru/item.asp?id=36997782, last accessed 2021/02/17

7. L. Schnieder, D. Wermser, M. Barrilero, Integrated Modelling of Business Processes and Communication Events for Public Transport, 233-242 (2014)

8. M. Ferretti, F. Schiavone, Journal of Business Process Management 22(2) (2016) https://doi.org/10.1108/BPMJ-05-2015-0079

9. F. A. Cummins, Next-Generation Business Process Management (BPM), Building the Agile Enterprise, 115-154 (2017) http://dx.doi.org/10.1016/b978-0-12-8051603.00004-1

10. M. Kirchmer, "Business process management: what is it and why do you need it?", High Performance Through Business Process Management, 1, 1-28 (2017) http://dx.doi.org/10.1007/978-3-319-51259-4_1

11. R. Elbert, H. Pontow, A. Benlian, Electronic Markets 27(2), 157-173 (2016) http://dx.doi.org/10.1007/s12525-016-0216-3

12. Z. Besri, A. Boulmakoul, Transportation Research Procedia 22, 164-173 (2017) http://dx.doi.org/10.1016/j.trpro.2017.03.023

13. L. Heilig, S. Voß, Information Technology and Management 18(3), 79-201 (2016) http://dx.doi.org/10.1007/s10799-016-0269-1

14. M. G. Cimino, F. Palumbo, G. Vaglini, E. Ferro, N. Celandroni, D. La Rosa, Information Technology and Management 18(3), 223-239 (2017)

15. Q. Zeng, Y. Feng, Z. Chen, Maritime Economics and Logistics 19(3), 474-503 (2017) http://dx.doi.org/10.1057/mel.2016.2

16. F. Córdova, C. Durán, Ann. Data. Sci. 1, 191-208 (2014) https://doi.org/10.1007/s40745-014-0014-8, https://doi.org/10.1007/s40745-014-0014$8 \mathrm{https} / / /$ iopscience.iop.org/article/10.1088/1757-899X/940/1/012023/pdf

17. P. Saragiotis, Maritime Business Review 4(1), 49-70 (2019) https://doi.org/10.1108/MABR-10-2018-0042, https://www.emerald.com/insight/content/doi/10.1108/MABR-10-2018-0042/full/html

18. T. Saati, Decision making. Hierarchy analysis method. M. Radio and Communication (1999)

19. E. A. Bagirov, S. A. Borodulina, Transport Business 4, 25-28 (2017) 